\title{
Signos para diagnosticar deshidratación en niños
}

\author{
Signs for diagnosing dehydration in children
}

\section{Objetivo}

Determinar la precisión y la exactitud de las manifestaciones clínicas para el diagnostico de deshidratación en niños de un mes a cinco años.

\section{Fuente de datos}

De un total de 26 artículos indentificados en Medline, la Biblioteca Cochrane, libros y colecciones privadas de expertos;
Steiner M y col. JAMA. 2004; 291 (22): 2746-2754

y luego de que dos de los tres autores evaluaran en forma independiente su metodología, fueron seleccionados 13. Incluyeron un total 1246 pacientes de dos semanas a 15 años de edad que habían sido internados por diarrea, vómitos, distrés respiratorio y/o deshidratación.

Resultados

Ver tabla 1.

Tabla 1: rédito diagnóstico de los hallazgos clínicos evaluados para determinar el grado de deshidratación en niños. Las características operativas referidas a cada manifestación o a sus conjuntos están referidas a la determinación de un $5 \%$ de deshidratación, salvo la regla de predicción que incluye siete de diez signos, que está referida a la determinación de un $10 \%$.

\begin{tabular}{|c|c|c|c|c|c|}
\hline & \multirow[b]{2}{*}{ GD } & \multicolumn{2}{|c|}{$\begin{array}{l}\text { Coeficiente de probabilidad o } \mathbf{L R}^{\mathrm{a}} \\
\text { (IC95\%) }\end{array}$} & \multicolumn{2}{|c|}{ Caracteristícas operativas (IC95\%) } \\
\hline & & Positiva & Negativa & Sensibilidad & Especificidad \\
\hline Retardo del relleno capilar & \multirow[t]{7}{*}{$5 \%$} & $4,1(1,7$ a 9,8$)$ & $0,57(0,4$ a 0,8$)$ & $60 \%(29$ a 91$)$ & $85 \%$ (72 a 98$)$ \\
\hline Signo del pliegue & & $2,5(1,5$ a 4,2$)$ & $0,66(0,6$ a 0,7$)$ & $58 \%$ (40 a 75$)$ & $76 \%$ (59 a 93 ) \\
\hline Anormalidad en el patrón respiratorio & & $2,0(1,5$ a 2,7$)$ & $0,76(0,6$ a 0,9$)$ & $43 \%$ (31 a 55$)$ & $79 \%$ (72 a 86$)$ \\
\hline Hundimiento ocular & & $1,7(1,1$ a 2,5$)$ & $0,49(0,4$ a 0,6$)$ & $75 \%$ (62 a 88$)$ & $52 \%$ (22 a 81$)$ \\
\hline Sequedad de las mucosas & & $1,7(1,1$ a 2,6$)$ & $0,41(0,2$ a 0,8$)$ & $86 \%(80$ a 92$)$ & $44 \%$ (13 a 74$)$ \\
\hline Mal aspecto general & & $1,9(0,97$ a 3,8$)$ & $0,46(0,3$ a 0,6$)$ & $80 \%(57$ a 100$)$ & $45 \%(10$ a 100$)$ \\
\hline Dos de cuatro signos & & $6,1(3,8$ a 9,8$)$ & \multicolumn{3}{|c|}{$\begin{array}{l}\text { 1) retardo del relleno capilar, 2) sequedad de las mucosas, 3) ausencia de lágrimas, 4) mal } \\
\text { aspecto general }\end{array}$} \\
\hline Siete de los diez signos & $10 \%$ & $8.4(5$ a 14,3$)$ & \multicolumn{3}{|c|}{$\begin{array}{l}\text { Los cuatro anteriores más: 5) disminución de la elasticidad de la piel, 6) anormalidad en la } \\
\text { respiración, 7) hundimiento ocular, 8) alteración del pulso radial, 9) más de } 150 \text { latidos por } \\
\text { minuto, 10) oliguria. }\end{array}$} \\
\hline Tres de los diez signos & \multirow{3}{*}{$5 \%$} & $4,9(3,3$ a 7,2$)$ & $0,15(0,1$ a 0,3$)$ & $87 \%(\mathrm{NR})$ & $82 \%(\mathrm{NR})$ \\
\hline Más de $96,3 \mathrm{mg} / \mathrm{dL}$ de urea & & $46,1(2,9$ a 733$)$ & $0,58(0,49$ a 0,68$)$ & $43 \%$ (34 a 52$)$ & $99 \%(96$ a 100$)$ \\
\hline Menos de $17 \mathrm{meq} / \mathrm{L}$ de $\mathrm{HCO}^{3}$ & & $3,5(2,1$ a 5,8$)$ & $0,22(0,12$ a 0,43$)$ & $83 \%$ (72 a 94$)$ & $76 \%$ (64 a 88$)$ \\
\hline
\end{tabular}

GD: grado de deshidratación determinado por dicha manifestación clínica o por su conjunto. LR: likelihood ratio. NR: no reportado.

\section{Conclusiones}

Los signos individuales más útiles para determinar la presencia de deshidratación en niños son el retardo del relleno capilar, el signo del pliegue y la anormalidad en el patrón respiratorio, mejorando su agrupamiento el rédito diagnóstico.

Palabras clave: deshidratación, niños, sensibilidad, especificidad, diagnóstico. Key words: dehydration, children, sensitivity, specificity, diagnosis.

Fuente de financiamiento: Fundación Robert Word Johnson.

\section{Comentario}

La habilidad para diagnosticar el grado de deshidratación en forma rápida y exacta en infantes y niños determina el tratamiento que se les asignará, mientras que la sobreestimación o subestimación de su grado de deshidratación podría aumentar los costos en salud y producir morbilidad innecesaria.

La bibliografía que evalúa las manifestaciones clínicas de deshidratación tiene limitaciones que pueden afectar la validez interna y externa de estos hallazgos. Por ejemplo, la referida al test de referencia contra el cuál fueron valorados cada signo clínico o su agrupamiento en forma de regla de predicción. En este sentido, el grado de deshidratación suele determinarse como la diferencia porcentual entre el peso del paciente mientras está deshidratado y el posterior a su rehidratación cuando ya se encuentra normohidratado. Sin embargo, algunos estudios identificados tomaron el "peso del paciente rehidratado" en diferentes momentos, lo que dificulta su agrupación; mientras que otros consideraron como peso del paciente rehidratado al que se mantenía en el tiempo o incorporaron otras variables como la densidad urinaria; pudiendo estas diferencias sesgar los resultados.

\section{Conclusiones de la comentadora}

A pesar de lo expresado, no contamos con mejor evidencia sobre el rédito diagnóstico de las diferentes manifestaciones clínicas de deshidratación que la aportada por la revisión de Steiner y col.

Carolina Carrara [ Servicio de Medicina Familiar y Comunitaria del Hospital Italiano de Buenos Aires. carolina.carrara@ @ospitalitaliano.org.ar ] 